\title{
ASPECTOS FONOLÓGICOS EM CRIANÇAS PRÉ-TERMO, NA FAIXA ETÁRIA DE 12 A 25 MESES
}

\author{
Kyvia Fernanda Tenório da SILVA (DD \\ Faculdade de Letras - Universidade Federal de Alagoas (UFAL) \\ Luzia Miscow da Cruz PAYÃO (DD \\ Universidade Estadual de Ciências da Saúde de Alagoas (UNCISAL)
}

ఠ

\section{OPEN ACCESS}

EDITADO POR

- Miguel Oliveira, Jr. (UFAL)

- René Almeida (UFS)

REVISADO POR

- Beatriz Medeiros (USP)

- Ubiratã Alves (UFRGS)

SOBRE OS AUTORES

- Kyvia Fernanda Tenório da Silva Investigação, Visualização e Escrita Rascunho Original.

- Luzia Miscow da Cruz Payão Conceptualização, Curadoria de Dados, Análise Formal, Aquisição de Financiamento, Investigação, Metodologia, Administração do Projeto, Recursos, Supervisão, Validação e Escrita - Análise e Edição.

DATAS

- Recebido: 05/02/2020

- Aceito: 20/08/2020

- Publicado: 17/09/2020

COMO CITAR

SILVA, Kyvia F. T.; PAYÃO, Luzia M. C. (2020). Aspectos fonológicos em crianças pré-termo, na faixa etária de 12 a 25 meses. Cadernos de

Linguística, v. 1, n. 2, p. 01-18.

\section{RESUMO}

Objetivo: analisar os aspectos fonológicos empregados na fala de crianças prematuras. Método: estudo observacional e descritivo da produção de fala espontânea em onze crianças prematuras durante seis meses de avaliações. Os pré-termo são de ambos os sexos, nascidos com idade gestacional entre 24 e 35 semanas, independente do peso, sendo avaliados entre 12 e 25 meses de idade. Inicialmente, consultou-se o prontuário do bebê, em seguida procedeu-se a anamnese fonoaudiológica e análise de fala espontânea entre criança e mãe em situação lúdica, seguindo-se os preceitos éticos, com o consentimento e a assinatura dos responsáveis. Foram computados em tabelas os totais das produções verbais e quantificado o preenchimento segmental vocálico e consonantal em sílabas tônica e átonas. Resultados: dentre os participantes, o participante S2 apresentou-se defasado em relação às demais crianças quanto ao total de palavras e ao preenchimento consonantal e vocálico em todas as posições silábicas das palavras produzidas. Os participantes S1, S8, S10 e S11 destacaram-se nos segmentos consonantais presentes na pré-tônica, tônica e pós-tônica, resultando em palavras mais inteligíveis. Conclusão: a sílaba tônica foi a detentora de maior preenchimento segmental. A distinção entre os segmentos consonantal e vocálico favoreceu a produção de novas palavras, refletidas no aumento do vocabulário.

\section{ABSTRACT}


Purpose: to assess the phonological aspects used in the speech of premature children. Methods: a descriptive observational study of spontaneous speech production in eleven premature children over a six-month period. They were male and female, had gestational age at birth between 24 and 35 weeks and, regardless of weight, were evaluated from the age of 12 to 25 months. Initially, the baby's chart was consulted, followed by speech-language anamnesis and analysis of spontaneous speech between child and mother in a play situation. Ethical standards were adhered to and a written informed consent was given. The verbal productions of words were computed in tables and the vowel and consonantal segmental filling in tonic and atonic syllables were quantified. Results: among subjects, subject 2 was out of time in relation to the other children in terms of total words and consonant and vowel filling in all syllabic positions of the words produced. Subjects 1, 8, 10 and 11 stood out with statistical difference in the consonant segments present in the pre-tonic, tonic and post-tonic, resulting in words that are more intelligible. Conclusion: greater segment filling was seen in the stressed syllable. The distinction between consonantal and vowel segment favored the production of new words, reflected in the increase in vocabulary.

\section{PALAVRAS-CHAVE}

Linguagem; Fala; Vocabulário; Criança; Prematuro.

\section{KEYWORDS}

Language; Speech; Vocabulary; Child; Premature. 


\section{INTRODUÇÃO}

O sistema fonológico de toda língua é constituído de segmentos que se contrastam, bem como de unidades prosódicas que são responsáveis pela organização da sequência de sons da fala. As crianças antes de falar já demonstram, por meio da linguagem não verbal, que possuem sensibilidade auditiva à prosódia da língua, expressa no ritmo e na entonação do input materno (SCARPA, 1999; LANGUS; NESPOR, 2013).

A fala surge em torno de um ano de vida nas crianças a termo e de desenvolvimento típico (LAMPRECHT et al., 2004). Nessa fase, há o acréscimo progressivo dos segmentos consonantais e vocálicos; e, na tentativa de produzir a palavra-alvo, ocorre o preenchimento das sílabas componentes, inicialmente com a tônica e em seguida as átonas (PAYÃO; COSTA, 2016).

O processo de adquirir os segmentos pode ser explicado por dois movimentos de análise fonológica: no movimento de direção centrípeta, a criança prioriza o que se mostra saliente no enunciado do input linguístico, segmentando a sílaba mais forte de uma dada palavra. No de direção centrífuga, oposta, há o preenchimento da cadeia sonora das sílabas átonas (PAYÃO, 2010).

Os segmentos consonantais e vocálicos do sistema fonológico, segundo Clements e Hume (1995), são formados por um conjunto de traços distintivos e há uma hierarquia nos traços que constituem determinado segmento. A partir disso, Mota (1997) propôs a hierarquia de traços contrativos das dezenove consoantes do português brasileiro, elaborando o Modelo Implicacional de Complexidade de Traços (MICT).

A obtenção do inventário segmental, em diferentes línguas, tem-se mostrado gradativo, pois a criança passa por diferentes estágios, podendo produzir inicialmente onomatopeias e palavras monossílabas até adquirir os sons e preencher as estruturas silábicas pertencentes à língua-alvo (MATZENAUER; MIRANDA, 2009; MATZENAUER, 2015).

No processo de aquisição segmental, as crianças inicialmente atentam para as vogais por apresentarem maior saliência perceptual auditiva, contribuindo para a produção de estruturas silábicas compostas apenas por vogais como onomatopeias (MATZENAUER, 2015; PAYÃO; COSTA, 2016).

À medida que os contrastes dos segmentos consonantais são percebidos com o amadurecimento auditivo e neurológico, há o preenchimento de estrutura silábica constituída de consoante e vogal presente em palavras dissílabas. O preenchimento contribui também para, posteriormente, adquirir-se sílaba com encontro consonantal (PAYÃO; COSTA, 2016).

A exposição ao input linguístico possibilita que a criança perceba as distinções fonológicas e adquira todos segmentos da língua-alvo. Se a criança for privada dessa exposição do input linguístico, a aquisição fonológica será comprometida, acarretando uma fala ininteligível (WIETHAN; MOTA; MORAES, 2016a). 
Na aquisição da linguagem em bebês prematuros, o desenvolvimento linguístico pode apresentar-se defasado. O estudo de Ragó et al. (2014) comparou os bebês pré-termo com baixo peso ao nascer e os a termo na faixa etária de seis a dez meses de idade, constatando que os prematuros são predispostos aos déficits linguísticos em razão do atraso da informação prosódica manipulada ao nível da palavra.

Monteiro-Luperi et al. (2016) analisaram a existência de atraso em prematuros, aos 2 anos de idade, em dois contextos diferentes: no primeiro, compararam-se a idade linguística apontada no teste TELD-3 e a idade correspondente ao nascimento; no segundo contexto, confrontaram-se a idade linguística e a idade corrigida dos participantes, atribuindo o nascimento de 40 semanas. $O$ estudo indicou que não houve diferença significativa entre as duas situações, mostrando que o atraso de linguagem, aos 2 anos de idade em prematuro, não é compensado pela correção de idade (MONTEIRO-LUPERI et al., 2016).

Os prematuros apresentaram pior desempenho linguístico, sobretudo no que tange à linguagem expressiva, tendo como fatores de risco o menor peso ao nascer e o maior grau de prematuridade (ZERBETO; CORTELO; FILHA, 2015).

Há um consenso entre os estudos citados acima, revelando que os pré-termo podem apresentar atraso na aquisição e no desenvolvimento da linguagem. Esse atraso pode ser manifestado nos primeiros anos de vida da criança pela ausência da fala ou por apresentar um sistema fonológico restrito, acarretando a fala ininteligível, podendo trazer repercussões no período da alfabetização.

Medidas de prevenção e intervenção fonoaudiológica são possíveis por meio da investigação e do monitoramento da aquisição de linguagem nos anos inicias da vida da criança, reduzindo os impactos da prematuridade no desenvolvimento linguístico desse grupo de risco.

Há diversos estudos que tratam do desenvolvimento típico de linguagem, mas ainda são poucos os que se reportam ao desenvolvimento de linguagem em prematuros relacionados aos aspectos prosódicos no Português Brasileiro (PB).

Esta pesquisa teve como objetivo geral analisar os aspectos fonológicos empregados na fala de crianças pré-termo, quantificando os segmentos vocálicos e consonantais produzidos no preenchimento segmental correspondente às sílabas tônica, pré-tônica e póstônica nas palavras produzidas. Também buscou-se comparar a cronologia de aquisição dos segmentos vocálicos e consonantais do português brasileiro. O estudo partiu da hipótese de que estas crianças avaliadas apresentavam atraso na aquisição prosódica quanto ao preenchimento segmental consonantal e vocálico das posições silábicas - pré-tônica, tônica e pós-tônica.

Como objetivo específico, o estudo buscou comparar os dados coletados entre os participantes da pesquisa, tendo como referência aqueles apontados pela literatura sobre desenvolvimento linguístico típico do PB. 


\section{MÉTODO}

A presente pesquisa caracterizou-se por ser uma análise de dados de fala, de caráter longitudinal e descritivo. Foram analisadas produções orais de crianças prematuras na faixa etária de 12 a 25 meses, recrutadas de uma maternidade Assistência de Média e Alta Complexidade, sendo Referência Estadual no Atendimento à Gestante de Alto Risco no município de Maceió. As amostras de fala compõem um banco de dados de projeto de pesquisa de iniciação científica aprovado pelo Comitê de Ética em Pesquisa de uma instituição de ensino superior, sob o CAAE $n^{\circ} 78027717.0 .0000 .5011$.

Foram acompanhadas oito crianças entre os anos de 2014 e 2016, utilizando-se da mesma metodologia para a coleta de dados - a partir de fala produzida espontaneamente -, e os procedimentos de descrição e análise estatística, procedimentos esses relatados no atual trabalho. Incluíram-se três crianças prematuras no período de 2016-2017. Portanto, incluíram-se dados das oito crianças, do período supracitado de um banco de dados já coletado, e foram coletados dados de fala espontânea de mais três crianças, totalizando 11 (onze) participantes. As cinco crianças do gênero masculino e as seis do gênero feminino foram avaliadas entre 12 e 25 meses de idade. A Tabela 1, a seguir, traz a caracterização dos participantes da pesquisa quanto aos dados gestacionais e socioculturais.

\begin{tabular}{|c|c|c|c|c|c|c|}
\hline $\begin{array}{l}\text { Participante } \\
\text { s }\end{array}$ & Gênero & $\begin{array}{l}\text { Idade } \\
\text { Gestacional }\end{array}$ & $\begin{array}{l}\text { Peso ao } \\
\text { nascer }\end{array}$ & $\begin{array}{l}\text { Escolarida } \\
\text { de da mãe }\end{array}$ & $\begin{array}{l}\text { Escolarização da } \\
\text { criança } \\
\text { Educação Infantil }\end{array}$ & $\begin{array}{l}\text { Tempo total } \\
\text { de internação }\end{array}$ \\
\hline S1 & Feminino & 27 semanas & $905 \mathrm{~g}$ & Ensino Médio & Sim & 90 dias \\
\hline S2 & Masculino & 32 semanas & $1.080 \mathrm{~g}$ & Ensino Médio & Não & 60 dias \\
\hline S3 & Masculino & 30 semanas & $1.135 \mathrm{~g}$ & Ensino Médio & Não & 60 dias \\
\hline S4 & Masculino & 30 semanas & $960 \mathrm{~g}$ & Ensino Médio & Não & 60 dias \\
\hline S5 & Feminino & 24 semanas & $785 g$ & Ensino Fundan & mental II & 108 dias \\
\hline S6 & Masculino & 29 semanas & $1.445 \mathrm{~g}$ & Ensino Médio & Não & 45 dias \\
\hline S7 & Feminino & 32 semanas & $1.355 \mathrm{~g}$ & Ensino Médio & Não & 38 dias \\
\hline S8 & Feminino & 33 semanas & $1.835 \mathrm{~g}$ & Ensino Médio & Não & 16 dias \\
\hline S9 & Feminino & 35 semanas & $2.245 g$ & Ensino Fundan & mental II & 7 dias \\
\hline S10 & Masculino & $\begin{array}{l}25 \text { semanas } \\
\text { e } 4 \text { dias }\end{array}$ & $890 \mathrm{~g}$ & Ensino Médio & Não & 103 dias \\
\hline S11 & Feminino & $\begin{array}{l}30 \text { semanas } \\
\text { e } 3 \text { dias }\end{array}$ & $1.190 \mathrm{~g}$ & Ensino Médio & Não & 47 dias \\
\hline
\end{tabular}

Tabela 1. Caracterização dos participantes da pesquisa quanto aos dados gestacionais e socioculturais. 
As crianças foram autorizadas pelos responsáveis para participar deste estudo, mediante a assinatura de Termo de Consentimento Livre e Esclarecido. As crianças com problemas neurológicos e/ou auditivos, que pudessem acarretar alterações previsíveis nos aspectos de linguagem e no desenvolvimento cognitivo, foram excluídas do estudo.

Com relação à coleta de dados, com o propósito de averiguar se as crianças correspondiam aos critérios de inclusão e exclusão, foi realizada inicialmente uma anamnese com objetivo de obter informações sobre condições do nascimento, amamentação, dados atuais de alimentação, desenvolvimento motor, desenvolvimento cognitivo/linguístico/escolaridade, intercorrências patológicas, antecedentes familiares (aspectos cognitivo-linguístico/socioafetivos) e ambiente familiar da criança.

Foi realizada uma avaliação da fala espontânea das crianças, as quais eram motivadas a interagir por meio de estratégias lúdicas com aproximadamente 60 brinquedos, de várias categorias semânticas (animais, bonecos, meios de transporte, alimentos, utensílios domésticos, entre outros) dispostos num tapete no chão da sala, resgatando-se experiências de vida diária e contextualizadas para a faixa etária da criança. Quando necessário, a pesquisadora interferia na interação, incentivando o diálogo entre a mãe biológica e a criança, ou indicando formas de explorar e manusear os brinquedos, para que houvesse situações do input da mãe biológica para a criança.

Com a finalidade de garantir o manuseio seguro e atrativo para a criança, todos os brinquedos foram selecionados segundo a adequação para a faixa etária acompanhada, de acordo com a classificação do Instituto Nacional de Metrologia, Normalização e Qualidade Industrial (Inmetro), vinculado ao Ministério do Desenvolvimento, Indústria e Comércio Exterior. A interação da criança com o adulto foi registrada por meio de áudio digital.

As coletas ocorreram em seis momentos de avaliação, com intervalo mensal com duração de trinta minutos de registro em áudio de dados de fala espontânea em cada sessão. Os áudios foram escutados pela avaliadora, as produções verbais identificadas foram transcritas com o Alfabeto Fonético Internacional e as transcrições realizadas foram conferidas por mais duas pessoas. Foram computados em tabelas os totais de palavras produzidas pelos participantes em cada coleta e quantificados os preenchimentos segmentais consonantais e vocálicos correspondentes às sílabas tônica, pré-tônica e pós-tônica.

Ao final dos seis meses de acompanhamento, os responsáveis receberam devolutivas sobre o desenvolvimento linguístico de seus filhos. Além disso, as crianças foram encaminhadas, durante a realização da coleta, para as avaliações auditivas, pediátricas, otorrinolaringológicas e, quando necessário, também fisioterápicas. Todos essas avaliações e exames eram disponibilizados no próprio serviço de atendimento terapêutico onde este estudo se desenvolveu.

Ao final das coletas, os dados foram computados em tabelas no Excel. Para comparação da aquisição total de palavras entre os participantes, e comparação dos totais de 
preenchimentos consonantais e vocálicos das posições silábicas - pré-tônica, tônica e póstônica -, no período citado, os dados obtidos foram submetidos ao teste de Lilliefors, para verificar o pressuposto de normalidade e, em seguida, ao Teste de Levene para verificar outro pressuposto, o de homogeneidade das variâncias dos resíduos, sendo esses pressupostos de parametrização. Quando atendidos os pressupostos, e por se tratar de comparação de mais de dois grupos, os dados foram submetidos à análise de variância Two Way (dois fatores) e One Way (um fator) e teste de Tukey para comparações múltiplas ( $p \leq 0,05)$.

Não sendo atendidos os pressupostos, utilizou-se o teste de Kruskal Wallis e teste Dunn's para comparações múltiplas $(p \leq 0,05)$. Ao realizar ANOVA e Tukey utilizou-se a média como medida de tendência central, já ao se realizar o teste de Kruskal Wallis e Dunn's utilizou-se a mediana.

\section{RESULTADOS}

A análise dos dados de fala relacionada ao total de palavras diferiv entre todos participantes e entre todas coletas. Além disso, S1, S8, S10 e S11 apresentaram as maiores médias de 55, 70, 59 e 62, respectivamente. Entretanto, S2 revelou-se defasado em relação aos demais participantes, com média de 6,2.

A partir da terceira coleta houve o aumento do repertório verbal dos pré-termo quando comparadas as médias dos participantes ao longo das seis coletas, contribuindo para que os dados fossem significativos, especialmente, na sexta coleta que apresentou a maior média.

A Tabela 2 apresenta as médias do total de palavras das crianças ao longo das avaliações.

\begin{tabular}{|c|c|c|c|}
\hline Participantes & Média & Tukey+ & Ftratamento (Valor de p) \\
\hline S1 & 55 & $a b$ & 6,8979 \\
\hline S2 & 6 & c & $(p<0,0001)$ \\
\hline S3 & 38 & bc & \\
\hline S4 & 41 & $\mathrm{~b}$ & \\
\hline S5 & 31 & $\mathrm{bc}$ & \\
\hline S6 & 24 & bc & \\
\hline S7 & 44 & b & \\
\hline S8 & 70 & a & \\
\hline s9 & 31 & $b c$ & \\
\hline $\mathrm{S} 10$ & 59 & $a b$ & \\
\hline S11 & 62 & $a$ & \\
\hline Períodos & Média & Tukey & Fblocos (Valor de p) \\
\hline
\end{tabular}




\begin{tabular}{llll}
\hline 1 Coleta & 15 & $d$ & \\
\hline 2 Coleta & 27 & $c d$ & 13,518 \\
\hline 3 Coleta & 40 & $b c$ & $(p<0,0001)$ \\
\hline 4 Coleta & 45 & $c$ & \\
\hline 5 Coleta & 52 & $b$ & \\
\hline 6 Coleta & 71 & $a$ & \\
\hline
\end{tabular}

Tabela 2. Comparação das médias do total de palavras. Dados submetidos à Análise de Variância dois critérios e teste Tukey para comparações múltiplas. $\alpha=0,05$

'Médias seguidas pela mesma letra nas colunas não diferem entre si, pelo teste Tukey, $(p<0,05)$.

Quanto ao preenchimento vocálico das sílabas, os participantes produziram de forma semelhante as sílabas pré-tônica e pós-tônica de palavras, diferindo na tônica. A tônica é a detentora de maior preenchimento segmental vocálico entre os participantes, sendo significativa em S1 ( $p<0.0001)$, S2 ( $p=0.0002)$, S3 ( $p=0.0313), S 4(p=0.006)$, S5 ( $p=0.0005), S 6(p=0.0002), S 7(p<0.0001), S 8(p=0.0005), S 9(p<0.0001), S 10(p=$ $0.0012)$ e $S 11$ ( $p=0.0008)$.

Em comparação aos demais participantes, S2 manteve-se defasado por apresentar produções com menos segmentos vocálicos nas sílabas pré-tônica, tônica e pós-tônica, apresentando as médias mais baixas, respectivamente, 1,67, 5,0 e 0,33, como evidenciado a seguir na Tabela 3.

\begin{tabular}{|c|c|c|c|c|c|}
\hline & & & & Ftratamento & $\mathrm{F}$ \\
\hline Preenchimentos & Médla & Desvlo Padrăo & Tukey' & (Valor de $\mathrm{p}$ ) & (Valor de p) \\
\hline Pré-Tônica & 6.17 & 1.0 & b & $<0,0001$ & 16,396 \\
\hline Tônıca & 11.83 & 1.0 & $a$ & & $(p<0,0001)$ \\
\hline Pós-Tônica & 6.33 & 0.8 & b & & \\
\hline & & & & 0,0002 & \\
\hline Preenchimentos & Médla & Desvlo Padrä́o & Tukey & & \\
\hline Pré-Tônica & 1,67 & 1,2 & $\mathrm{~b}$ & & \\
\hline Tônıca & 5,00 & 1,9 & $a$ & & \\
\hline Pós-Tônıca & 0,33 & 0,5 & b & & \\
\hline & & & & 0,0313 & \\
\hline Preenchimentos & Médla & Desvio Padräo & Tukey & & \\
\hline Pré-Tônica & 5,00 & 2,4 & $\mathrm{~b}$ & & \\
\hline Tônica & 9,00 & 1,8 & $a$ & & \\
\hline Pós-Tônica & 5,83 & 2,1 & $\mathrm{~b}$ & & \\
\hline & & & & 0,0060 & \\
\hline Preenchimentos & Médla & Desvlo Padrăo & Tukey & & \\
\hline Pré-Tônıca & 5,00 & 1,6 & b & & \\
\hline Tônıca & 9,50 & 2,7 & $\mathrm{a}$ & & \\
\hline
\end{tabular}




\begin{tabular}{|c|c|c|c|c|c|}
\hline Pós-Tônıca & & 6,17 & 2,0 & $\mathrm{~b}$ & \\
\hline & S5 & & & & 0,0005 \\
\hline Preenchimentos & & Médla & Desvio Padrão & Tukey & \\
\hline Pré-Tônıca & & 4,00 & 1,9 & b & \\
\hline Tônica & & 8,33 & 1,7 & $a$ & \\
\hline Pós-Tônica & & 4,33 & 1,3 & $\mathrm{~b}$ & \\
\hline & S6 & & & & 0,0002 \\
\hline Preenchimentos & & Médla & Desvlo Padrão & Tukey & \\
\hline Pré-Tônınıa & & 3,67 & 1,4 & $\mathrm{~b}$ & \\
\hline Tônica & & 9,00 & 1,8 & $a$ & \\
\hline Pós-Tônıca & & 3,67 & 2,1 & b & \\
\hline & S7 & & & & $<0,0001$ \\
\hline Preenchimentos & & Médla & Desvio Padrăo & Tukey & \\
\hline Pré-Tônıca & & 6,00 & 1,7 & $\mathrm{~b}$ & \\
\hline Tônıca & & 12,17 & 1,0 & $a$ & \\
\hline Pós-Tônica & & 6,00 & 1,9 & $\mathrm{~b}$ & \\
\hline & S8 & & & & 0,0005 \\
\hline Preenchimentos & & Médla & Desvio Padrăo & Tukey & \\
\hline Pré-Tônica & & 7,17 & 1,5 & b & \\
\hline Tônıca & & 11,33 & 2,0 & $a$ & \\
\hline Pós-Tônıca & & 6,50 & 1,5 & $\mathrm{~b}$ & \\
\hline & S9 & & & & $<0,0001$ \\
\hline Preenchimentos & & Médıa & Desvlo Padrăo & Tukey & \\
\hline Pré-Tônıca & & 3,83 & 2,0 & $\mathrm{~b}$ & \\
\hline Tônica & & 10,67 & 1,9 & $a$ & \\
\hline Pós-Tônıca & & 4,17 & 1,7 & $\mathrm{~b}$ & \\
\hline & S10 & & & & 0,0012 \\
\hline Preenchimentos & & Médıa & Desvio Padrăo & Tukey & \\
\hline Pré-Tônıca & & 8,00 & 2,1 & $\mathrm{~b}$ & \\
\hline Tônıca & & 12,17 & 1,8 & $\mathrm{a}$ & \\
\hline Pós-Tônıca & & 6,17 & 2,6 & b & \\
\hline & S11 & & & & 0,0008 \\
\hline Preenchimentos & & Médıa & Desvio Padrăo & Tukey & \\
\hline Pré-Tônıca & & 7,17 & 2,2 & b & \\
\hline Tônıca & & 12,00 & 2,6 & $a$ & \\
\hline Pós-Tônica & & 5,33 & 2,2 & b & \\
\hline
\end{tabular}

Tabela 3. Comparação das médias do total de vogais por participante. Dados submetidos à Análise de Variância e teste Tukey para comparações múltiplas. $\alpha=0,05$

†Médias seguidas pela mesma letra minúscula nas colunas não diferem entre si, pelo teste Tukey, $(p<0,05)$ 
O preenchimento consonantal na posição C1 das sílabas pré-tônicas, tônicas e pós-tônicas foi significativo apenas em $S 1(p=0.0075), S 2(p=0.0007), S 3(p=0.0313)$ e $S 6$ $(p=0.0005)$; a passo que S4, S5, S7, S8, S9, S10 e S11 comportaram-se de forma semelhante quanto ao preenchimento consonantal.

Confirmou-se a defasagem de $\mathrm{S} 2$ em relação aos demais participantes com a menor quantidade de média de consoantes na posição $C 1$ nas sílabas pré-tônica, tônica e póstônica. Por sua vez, S1, S8, S10 e S11 apresentaram as médias mais altas no preenchimento consonantal das sílabas pré-tônicas, tônicas e pós-tônicas, revelando o inventário segmental consonantal mais completo, o que possibilitou estabelecer maior contraste entre as palavras.

A Tabela 4 mostra o preenchimento consonantal na posição $C 1$ nas sílabas pré-tônicas, tônicas e pós-tônicas das crianças ao longo das avaliações.

\begin{tabular}{|c|c|c|c|c|c|c|}
\hline & s1 & & & & Ftrutarmentc & $F$ \\
\hline Preenchimentos & & Média & Desvio Podroo & Tukey" & (Valor de p) & (Valor de p) \\
\hline Pré-Tônica & & 6,3 & 1,2 & $\mathrm{~b}$ & 0,0076 & \multirow{21}{*}{$(p \leqslant 0,0001)^{10,07}$} \\
\hline Tônica & & 112 & 2,4 & $\mathbf{a}$ & & \\
\hline Pós-Tônica & & 8,00 & 2,9 & ab & & \\
\hline & s2 & & & & 0,0007 & \\
\hline Preenchimentos & & Médla & Desvio Padroo & Tukey & & \\
\hline Pré-Tônica & & 0,7 & 0,8 & b & & \\
\hline Tônica & & 2,00 & 0,6 & $\mathbf{a}$ & & \\
\hline Pós-Tônica & & 0.2 & 0,4 & b & & \\
\hline & s3 & & & & 0,0313 & \\
\hline Preenchimentos & & Médla & Desvio Podroo & Tukey & & \\
\hline Pré-Tônica & & 4,83 & 3,1 & b & & \\
\hline Tônica & & 10,60 & 3,8 & $\mathbf{a}$ & & \\
\hline Pós-Tônica & & 6,33 & 3,4 & ab & & \\
\hline & S4 & & & & 0,5695 & \\
\hline Preenchimentos & & Mêdıla & Desvio Padrao & Tukey & & \\
\hline Pré-Tônica & & 6,33 & 4,8 & $\mathbf{a}$ & & \\
\hline Tônica & & 10,00 & 3,6 & $\mathbf{a}$ & & \\
\hline Pós-Tônica & & 8,17 & 6,7 & $\mathbf{a}$ & & \\
\hline & S6 & & & & 0,0832 & \\
\hline Preenchimentos & & Mẻdla & Desvio Podroo & Tukey & & \\
\hline Pré-Tônica & & 3,83 & 2,7 & $\mathbf{a}$ & & \\
\hline
\end{tabular}




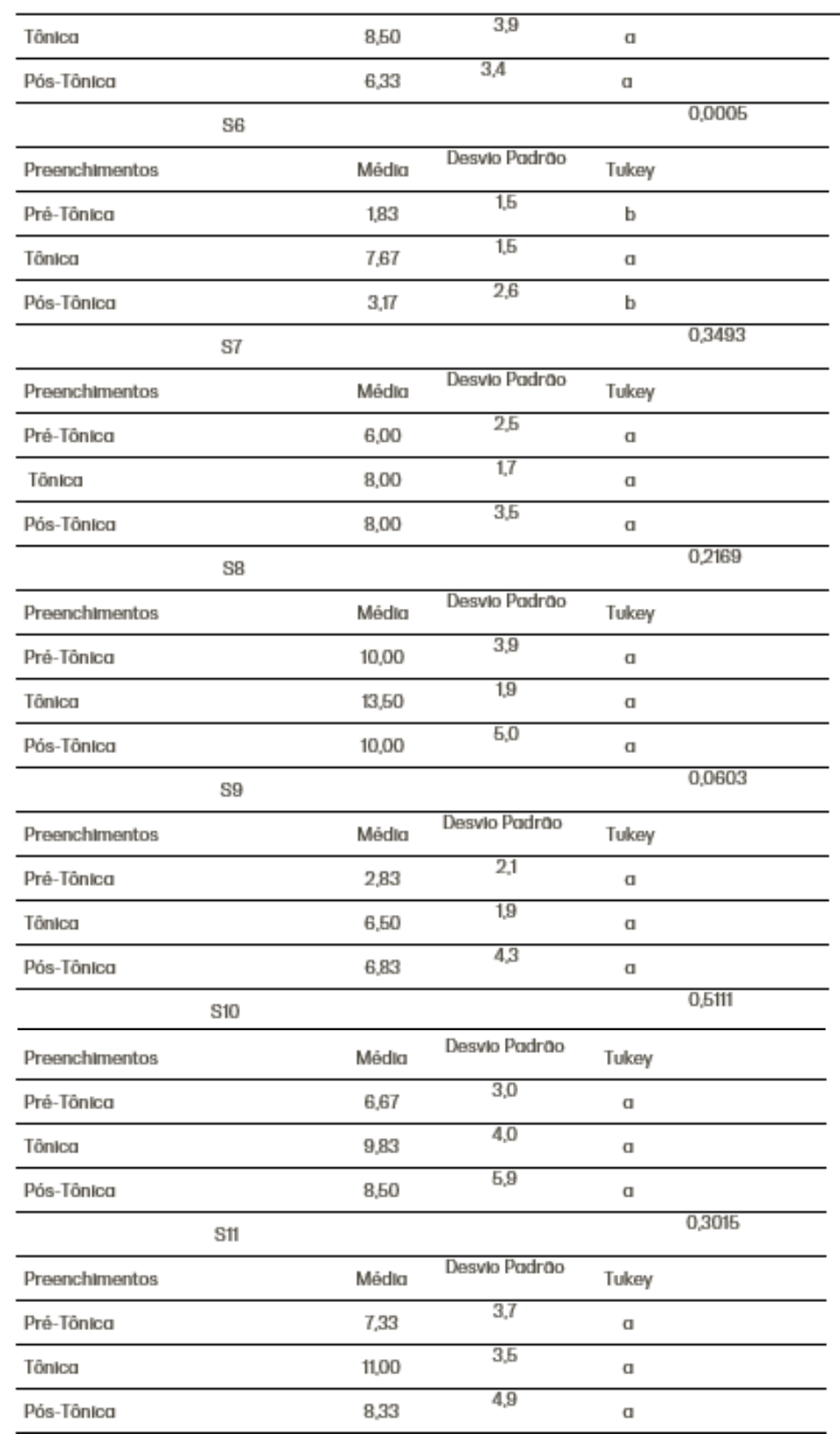

Tabela 4. Comparação das médias do total de consoantes por participante. Dados submetidos à Análise de Variância e teste Tukey para comparações múltiplas. $\alpha=0,05$

'Médias seguidas pela mesma letra minúscula nas colunas não diferem entre si, pelo teste Tukey, $(p<0,05)$.

\section{DISCUSSÃO}

Constatou-se que os participantes diferiram entre si quanto ao total da média de vocabulário e aos preenchimentos consonantais e vocálicos nas sílabas pré-tônicas, tônicas e pós- 
tônicas. Além disso, S2 revelou-se aquém em relação aos demais participantes. Por sua vez, as produções de S1 (1;9.4) [' e.tI] esse e [' doi] dois, S8 (1;9.17) [' bã.ka] branca e ['bo.tow] botou, S10 (1;8) [ba. 'ej.a] baleia e [ ' e.II] ele e S11 (1;8) [ka. 'va.lo] cavaloe [ka. ' de] cadêmostraram que eles estruturaram palavras muito próximas ao padrão da fala adulta, repercutindo na variedade de classes gramaticais empregadas e nas construções frasais observadas ao longo das avaliações.

Os prematuros podem apresentar risco para o desenvolvimento da linguagem, especialmente nos primeiros anos de vida, afetando a linguagem expressiva e receptiva (BRASIL, 2014). O comprometimento da aquisição inicial da linguagem deve-se ao tempo de internação que diminui a exposição do bebê ao input materno. Assim, a interação entre mãe e bebê é importante para a maturação cerebral e para a aquisição da linguagem (balbucio e primeiras palavras) (ZERBETO; CORTELO; FILHA, 2015).

Os recém-nascidos, apesar de terem pouca ou nenhuma experiência linguística, possuem conceitos linguísticos preestabelecidos, relativos à estrutura da sílaba, que moldam a percepção e a aquisição da linguagem (GÓMEZ et al., 2014). Além disso, os bebês, assim como os adultos, apresentam de maneira consistente padrões de preferências universais relativas à sonoridade, elegendo sílabas com estruturas silábicas menos complexas, respeitando o princípio de sonoridade (ALVARENGA; OLIVEIRA, 1997; GÓMEZ et al., 2014).

Observou-se, nas crianças da presente pesquisa, que elas realizam os processos fonológicos de redução de sílaba e harmonia consonantal, mantendo sempre a sílaba tônica, seguida da pós-tônica com estrutura silábica menos complexa do tipo CV, configurando, predominantemente, palavras reduzidas a duas sílabas. Assim, foram identificadas produções como: S1 (1;9.4) [' ko.la] escola, S11 (1;4) [' ne.ne] boneco e S10 (1;6) [' ta.ta] batata. Além disso, constatou-se a simplificação de estrutura silábica complexa como o apagamento de coda em S4 (1;7.3) [ ' po.ta] porta e S1 (1;8.21) [' po.kə] porco.

A especialização funcional de consoantes e vogais emerge durante a segunda metade do primeiro ano de vida em virtude das diferenças nos níveis acústico-fonéticos, e possivelmente, também dos níveis lexicais, o que levaria, em conjunto, ao papel privilegiado de consoantes para o processamento lexical (POLTROCK; NAZZI, 2015).

Os preenchimentos segmentais consonantais e os vocálicos diferiram nas produções verbais das crianças, repercutindo não apenas na quantidade de palavras produzidas, mas também na qualidade da manipulação desses segmentos, em razão da expansão do inventário fonológico, sendo as vogais as responsáveis pela marcação da prosódia e as consoantes pelo reconhecimento lexical (POLTROCK; NAZZI, 2015).

As produções de S2 concentravam-se mais na realização de vogais [i. ' ãw] leão S2 (1;4), que são os segmentos de maior sonoridade e preenchem o núcleo numa sílaba. De acordo com Poltrock e Nazzi (2015), os neonatais são capazes de reconhecer mais a informação transmitida por vogal do que por consoante no processamento linguístico inicial. Os dados 
da presente pesquisa revelam que a sílaba tônica foi a detentora de maior preenchimento vocálico por ter maior saliência acústica, colaborando para a organização fonológica na aquisição inicial, uma vez que o compartilhamento dos sons auxilia a pauta prosódica da produção da palavra-alvo.

O desempenho linguístico das crianças nas três primeiras coletas se manteve igual no que se refere às suas produções verbais. Entre a terceira e a quinta coleta, houve expansão no número de palavras, mas apenas na sexta foi que se destacaram. Essa expansão do vocabulário pode estar relacionada com o aumento da idade.

As poucas produções iniciais se devem à qualidade precária da interação entre a criança e seus responsáveis, durante o ato de brincar, sendo esclarecida a importância das interações lúdicas no ambiente familiar, podendo favorecer positivamente o desenvolvimento e desempenho da criança, pois quanto mais a criança estiver exposta à interação comunicativa com os pais, haverá mais condições para se desenvolver de acordo com o esperado para a sua idade. No decorrer das coletas, houve melhora da interação dos pais com os filhos, podendo ter influenciado no aumento do vocabulário.

Estudo mostra que crianças de 10 meses na aquisição inicial começam a categorizar distinções fonológicas a partir do input, posicionando consoantes e vogais na sílaba, ou seja, aprendem padrões fonotáticos por computação de configurações quanto às suas características fonológicas. Além disso, os autores sugerem que essas características fonológicas desempenham um papel importante na aquisição de regularidades fonotáticas nativas (GONZALEZ-GOMEZ; NAZZI, 2014).

As primeiras produções verbais das crianças deste estudo apresentavam os fonemas plosivos e nasais cujo ponto de articulação era compartilhado, representado pelos traços [labial] e [coronal]; e, quanto ao modo de articulação, representado pelo traço [-contínuo], como, por exemplo, em S1 (1;6.15) [po. ' po.ka] pipoca, S4 (1;11.10) [pa. ' pa.tə] sapato e em S5 $(1 ; 8.5)$ [' ta.bi.da] sabida.

Nas produções dos participantes S1 (1;11.25) [ta. ' ta.də] sentado e S7 (1;6.22) [' ka.da] ['ta.ta] ['ta.za] casa, constatou-se o espraiamento do traço [coronal], em ['ta.za] e [ta. 'ta.dv], na tentativa de produzir as palavras-alvo casa e sentado. Cabe observar que, nessa estratégia de natureza fonológica, tendo como meta a inclusão do traço [+contínuo] no sistema fonológico, torna-se uma tarefa mais complexa nessa fase inicial de aquisição dispor simultaneamente de traços diferentes quanto ao ponto e modo de articulação distribuídos entre as sílabas de uma mesma palavra.

Além disso, observou-se no token [' ta.ta], para casa, que a criança ainda se utiliza do recurso de reduplicação da sílaba por meio da harmonia consonantal, valendo-se dos mesmos segmentos para as duas sílabas, preservando a sua estrutura prosódica. Há o espraiamento do traço [coronal] do segmento /t/, em virtude da complexidade de coarticular traços diferentes [[dorsal], [-voz]] para a $1^{a}$ sílaba e os [[coronal], [+ contínuo], [+voz]] da $2^{a}$ sílaba 
da sequência, que exigem constrições simultâneas no trato vocal, na tentativa de produzir a palavra-alvo casa.

Nesse dado [' ta.ta] casa, a criança realiza a anteriorização de velar, a plosivização de fricativa, o ensurdecimento da consoante da sílaba pós-tônica nessa palavra, gerando a harmonia consonantal. Na fase de aquisição inicial, verifica-se a complexidade da coarticulação de palavras com traços distintivos que diferem quanto ao ponto e modo de articulação entre as sílabas constituintes, contribuindo para a produção de processos fonológicos.

Nos dados de S3 (1;6.11) [' ka.ə] [ka. ' ka.u] cavalo e S5 (1;8.26) [ka. ' pe.ka] sapeca, ocorreram o processo de assimilação do traço [dorsal] do segmento /k/, em virtude da dificuldade com a coocorrência com traços [[coronal] [+contínuo] [ミvoz]] para os segmentos / v/ e /s/. Em S10 (1;10) [gĩ. ' gĩ.nə] franguinho, observou-se o espraiamento do traço [dorsal] do segmento /9/ da sílaba tônica, substituindo o segmento-alvo da sílaba pré-tônica /f/, que se constitui dos traços [coronal] e [+contínuo].

Desde os cinco meses de idade as crianças fazem distinções lexicais baseadas em mudanças mínimas para vogais, muito antes de começarem a falar de maneira inteligível. À medida que crescem, aperfeiçoam sua capacidade de realizar distinções fonéticas finas para sons de fala mais curtos, correspondentes às consoantes. Dessa forma, tanto as distinções consonantais quanto as vocálicas são necessárias para aprender o léxico (BOUCHON et al., 2015).

Nos dados de fala dos participantes verificou-se a seleção de sons já disponíveis no seu inventário fonológico. Nessa fase de aquisição inicial, os fonemas /p, t, m, n/ com estado de complexidade zero são os primeiros a serem adquiridos, pois as estruturas e os traços não marcados estão presentes. Como a especificação do traço não se dá simultaneamente, a criança elege apenas um traço marcado, porque nesse momento ela possui dificuldade em usar dois traços (WIETHAN; MOTA; MORAES, 2016a; WIETHAN; MOTA; MORAES, 2016b).

No processo de aquisição consonantal, Lamprecht et al. (2004) aponta que a aquisição de plosivas ocorre por volta de 1;8; já a das fricativas dá-se gradualmente e as líquidas são adquiridas mais tardiamente. Em contrapartida, os participantes da pesquisa não seguiram essa ordem de aquisição, pois aos 1;8 não apresentavam nem todas as plosivas, completando-se essa classe segmental apenas com 1;10.

A partir da exposição do input linguístico e da maturação do sistema nervoso e auditivo ocorre a acurácia na produção de fala, obtendo-se novos traços distintivos de estruturas silábicas, refletindo-se num sistema com maior nível de complexidade. Assim, a expansão do sistema fonológico se dá pela distinção e pela combinação dos traços distintivos e a constituição do inventário de estruturas silábicas da língua (WIETHAN; MOTA; MORAES, 2016a; MATZENAUER, 2015). 
Matzenauer (2015) mostra que, na formação de classes de segmentos, como fato basilar na construção do inventário fonológico, à medida que o vocabulário aumenta há ordem de emergência dos segmentos. Na tentativa de produzir a palavra-alvo ocorre o preenchimento de espaço fonético-fonológico, empregando alternâncias/assimetrias/variabilidades. Além disso, pode haver o descompasso entre a capacidade de compreensão/percepção e a capacidade de produção linguística das crianças (MATZENAUER, 2015).

Entre o grupo de crianças, S2 apresentou produções verbais que se concentraram mais na realização de vogais. A qualidade de produção dos segmentos consonantais se mostrou defasada, limitando seu inventário fonológico-fonético a algumas plosivas e nasais com traços não marcados [p, $m, n]$, com o segmento /d/ contendo um traço marcado [+voz], pela plosiva /k/ com traços [-voz] [dorsal] e pelo fonema /9/ com traços [dorsal] [+voz]. Além disso, houve predomínio de preenchimento apenas da sílaba tônica, refletindo-se em palavras reduzidas a uma única sílaba em suas produções, como se constatam em [ ' p ] porta $(1 ; 6)$ e [' $\mathrm{kI}$ ] aqui (1;8).

A defasagem na qualidade e quantidade dos segmentos em S2 pode se relacionar às intercorrências neonatais, às comorbidades, como a broncodisplasia pulmonar, que afeta o cérebro imaturo e vulnerável (SANSAVINI et al., 2014), comprometendo o desenvolvimento global e linguístico, a problemas ortopédicos, que limitam a sua interação com o meio (VOHR, 2014) além da estimulação restrita dispensada pela mãe adolescente.

No grupo acompanhado, verificou-se que S1, S8, S10 e S11 destacaram-se, com uma maior quantidade de segmentos consonantais, evidenciada na produção de palavras constituídas por consoantes das classes segmentais de nasais (/m/, /n/, /n/), plosivas (/p/, /b/, /t/, /d/,/k/, /g/), fricativas (/f/, /v/, / / /,/3/,/s/, /z/), líquidas laterais (///, / / /) e não lateral (/r/), resultando em palavras mais inteligíveis.

O desempenho linguístico significativo nesses prematuros pode estar relacionado à boa interação comunicativa entre mãe e filho. Durante as avaliações se observou o resgate de experiências, rotinas e situações vivenciadas no ambiente familiar, expressadas por meio de comentários que a mãe realizava ao se comunicar com a criança, enquanto manuseavam os brinquedos em parceria. Fatores socioambientais e culturais interferem no desenvolvimento de linguagem do recém-nascido prematuro (CASKEY et al., 2014).

A maturação neurológica e auditiva possibilita o incremento gradual dos segmentos, permitindo diferenças quanto à classe de sons, à posição na sílaba e na palavra, de modo que a criança apresenta melhor percepção dos constituintes prosódicos que são organizados para a produção da fala encadeada. A hierarquia prosódica entre esses constituintes é iniciada a partir da segmentação da sílaba mais forte - a tônica de uma dada palavra -, (direção centrípeta), e o preenchimento das posições silábicas estruturais dessa tônica e de sílabas vizinhas, com a formação do pé métrico visando à palavra-alvo (direção centrífuga) (PAYÃO; COSTA, 2016). 
A aquisição prosódica quanto ao preenchimento segmental das posições silábicas - átonas e tônica revelou-se defasada, confirmando a hipótese deste estudo quanto à presença do atraso na aquisição e no desenvolvimento fonológico em prematuros. As crianças, inicialmente, realizaram a segmentação da sílaba tônica, sílaba esta sinalizada pela proeminência entonacional do enunciado do input, que orientou a segmentação silábica da palavra.

Essa segmentação acarretou a ocorrência do processo fonológico, no nível silábico, de não realização de uma sílaba ou mais da palavra, e na estruturação do pé métrico trocaico em alguns casos, como se observou nas produções dos participantes na sexta e última coleta: S1 (1;11) ['ta.ta] patata, S2 (1;8) ['ga] galinha, S3 (2;1) ['gi.sa] linguiça, S4 (2;1) ['fã.tI] elefante, S5 (1;8) ['a.v»] árvore, S6 (1;10) ['a.vI] árvore, S7 (1;11) ['le.la] cadeira, S8

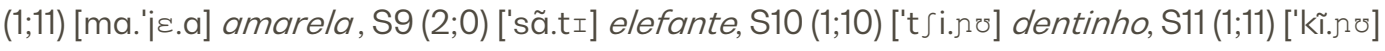
porquinho e ['ãw] macarrão.

Diversos fatores, tais como biológicos e sociais, associados à prematuridade podem desencadear os déficits na aquisição e no desenvolvimento da linguagem, visto que os prétermo tendem a se desenvolver de forma mais lenta, justificando ações preventivas que interceptem os distúrbios de comunicação. Pode-se inferir que a variabilidade dos resultados obtidos entre estes participantes prematuros deve-se a fatores biológicos e sociais, tais como peso ao nascer, idade gestacional, sexo e ambiente linguístico, podendo este último favorecer a compensação desses déficits de linguagem/fala.

\section{CONCLUSÃO}

A análise dos dados revela que a sílaba tônica foi a detentora de maior preenchimento segmental consonantal e vocálico ao confrontar os dados de todos os prematuros ao longo das seis coletas, corroborando a literatura ao indicar a sílaba tônica como a responsável por desencadear o preenchimento segmental e organizar os segmentos nas posições silábicas pré-tônica e pós-tônica.

Constatou-se a presença de atraso na aquisição prosódica quanto aos preenchimentos consonantais e vocálicos das posições silábicas - pré-tônica, tônica e pós-tônica entre os participantes deste estudo. Além disso, estes prematuros não seguem a ordem de aquisição fonológica observada em crianças de desenvolvimento típico, que apresentam todos os fonemas plosivos com 1;8 de idade, sendo que nestas crianças apenas com 1;10 o inventário dos fonemas plosivos se completou.

S2 é quem apresenta menor índice quantitativo de segmentos consonantais e vocálicos nas diferentes posições silábicas. Além disso, na comparação da aquisição total de palavras, $\mathrm{S} 2$ revela-se aquém em relação aos demais prematuros. 
Salienta-se que os dados de fala dos participantes foram coletados a partir da produção espontânea, o que permite que se aproximem à fala habitual da criança, trazendo informações fonético-fonológica, semântico-lexicais, morfossintática e pragmática.

Há necessidade de mais pesquisas que tratem da aquisição prosódica com um banco de dados mais robusto, que permitam fazer generalizações da aquisição fonológica desses participantes, incluindo-se procedimentos e instrumentos de avaliação linguística para esse grupo de risco. A partir disso, pretende-se contribuir com medidas de prevenção e intervenção precoce, minimizando possíveis sequelas para o desenvolvimento da criança.

\section{AGRADECIMENTOS}

As autoras agradecem ao CNPq e à FAPEAL pelo apoio financeiro concedido ao projeto de Iniciação Científica nos períodos: PIBIC 2014-2015; 2015-2016 e PROBIC 2016/2017 e, em especial, às onze famílias que participaram deste estudo longitudinal.

\section{REFERÊNCIAS}

ALVARENGA, D; OLIVEIRA, M.A. Canonicidade silábica e a aprendizagem da escrita. Revista de Estudos Lingǘsticos. Belo Horizonte, ano 6, n.5, v.1, p.127-158. 1997. [acesso em 17 de set 2019]. Disponível em: http://linguagemnaciencia.weebly.com/uploads/3/0/9/3/30933555/4canonicidade_silbica_e_aprendizagem_ da_escrita.pdf.

BOUCHON, Camillia; FLOCCIA, Caroline; FUX, Thibaut; ADDA-DECKER, Martine; NAZZI, Thierry. Call me Alix, not Elix: vowels are more important than consonants in own-name recognition at 5 months. Developmental Science, v. 18, n. 4, p.587-598, 2015.

BRASIL. Ministério da Saúde, Secretaria de Atenção à Saúde, Departamento de Ações Programáticas Estratégicas. Atenção à saúde do recém-nascido: guia para os profissionais de saúde. $2^{\mathrm{a}}$ ed. [Internet]. Brasília: Ministério da Saúde; 2014 [cited 2017 Jun 28]. Available from: http://bvsms.saude.gov.br/bvs/publicacoes/atencao_saude_recem_nascido_v1.pdf.

CASKEY, Melinda; STEPHENS, Bonnie; TUCKER, Richard; VOHR, Betty. Adult talk in the NICU with preterm infants and developmental outcomes. Pediatrics, v.133, n. 3, p. 578-584, 2014.

CLEMENTS, George Nick; HUME, Elizabeth. The internal organization of speech sounds. In: Goldsmith J, editor. The Handbook of Phonogical Theory. Cambridge: Blackwell, p. 245-306, 1995.

GÓMEZ, David Maximiliano; BERENT, Iris, BENAVIDES-VARELA, Silvia; BION RAH, Ricardo; CATTAROSSI, Luigi; NESPOR, Marina; MEHLER, Jacques. Language universals at birth. PNAS. v.111, n. 16, p. 5837-5841, 2014. Available from: https://doi.org/10.1073/pnas.1318261111.

GONZALEZ-GOMEZ, Nayeli; NAZZI, Thierry. Constraints on statistical computations at 10 months of age: the use of phonological features. Developmental Science, v. 18, n. 6, p. 864-876, 2014.

LAMPRECHT, Regina Ritter et al. Aquisição fonológica do português. Perfil de desenvolvimento e subsídios para terapia. Porto Alegre: ArtMed, 2004. 
LANGUS, Alan; NESPOR, Marina. Language development in infants: What do humans hear in the first months of life? Hearing, Balance and Commun. v. 11, n. 3, p. 121-9, 2013. Available from: https://doi.org/10.3109/21695717.2013.817133.

MATZENAUER, Carmem Lúcia Barreto; MIRANDA, Ana Ruth Moresco. Traços distintivos e a aquisição das vogais do PB. In: HORA, Dermeval da. (org.). Vogais no Ponto mais Oriental das Américas. João Pessoa: Ideia. p. $45-63,2009$

MATZENAUER, Carmen Lúcia Barreto. Gramática(s) fonológica(s) no processo de aquisição da linguagem: a construção do inventário segmental. Revista Prolíngua, v. 10, n. 1, p. 62-78, 2015. Acesso em: [acesso em 2017 Jun 25]. Disponível em: periodicos.ufpb.br/index.php/prolingua/article/download/27588/14827.

MONTEIRO-LUPERI, Telma lacovino; BEFI-LOPES, Debora Maria; DINIZ, Edna Maria Albuquerque; KREBS, Vera Lucia, CARVALHO, Werther Brunow de. Desempenho linguístico de prematuros de 2 anos, considerando idade cronológica e idade corrigida. São Paulo: CoDAS, v. 28, n. 2, p. 118-122, 2016. Acesso em: [acesso 2016 Jul 29] Disponível em: http://www.scielo.br/scielo.php?script=sci_arttext\&pid=S231717822016000200118\&lng=en . http://dx.doi.org/10.1590/2317-1782/20162015075.

MOTA, Helena Bolli. Aquisição segmental do português: um modelo implicacional de complexidade de traços. Tese (Doutorado) - Pontifícia Universidade Católica do Rio Grande do Sul, Porto Alegre, 1996.

NESPOR, Marina; VOGEL, Irene. Prosodic Phonology. Dordrecht: Foris Publications; 1986.

PAYÃO, Luzia Miscow da Cruz. Aquisição de fonologia: a influência do acento e o preenchimento de unidades prosódicas em dados de fala de duas crianças entre 1;0.4 e 2;1.10 de idade, em contato com o português brasileiro falado em Alagoas e Pernambuco. 192 p. Tese (Doutorado em Linguística) - Programa de PósGraduação em Letras e Linguística. Faculdade de Letras, Universidade Federal de Alagoas, Maceió, 2010.

PAYÃO, Luzia Miscow da Cruz; COSTA, Januacele Francisca da. Preenchimento de unidades prosódicas na aquisição fonológica inicial do português brasileiro. Porto Alegre: Letras de Hoje, v. 51, n. 3, p. 433-441, 2016.

POLTROCK, Silvana; NAZZI, Thierry. Consonant/vowel asymmetry in early word form recognition. Journal of Experimental Child Psychology, v. 131, p. 135-48, 2015.

RAGÓ, Anett; HONBOLYGÓ, Ferenc; RÓNA, Zsófia; BEKE, Anna; CSÉPE, Valéria. Effect of maturation on suprasegmental speech processing in full- and preterm infants: a mismatch negativity study. Res Dev Disabil. 2014 Jan;35 (1):192-202. doi: 10.1016/i.ridd.2013.10.006. Epub 2013 Oct 27.

SANSAVINI, Alessandra; JUSTICE, Laura; GUARANI, Annalisa; SAVINI, Silvia, ALESSANDRONI Rosina; FALDELLA, Giacomo. Language, motor and cognitive development of extremely preterm children: modeling individual growth trajectories over the first three years of life. Journal of Communication Disorders, v. 49, p. 55-68, 2014

SCARPA, Ester. Interfaces entre componentes e representação na aquisição da prosódia. In: LAMPRECHT, Regina Ritter, organizador. Aquisição da linguagem: Questões e análises. Porto Alegre: Edipucrs, Cap.1, p. 1738, 1999.

VOHR, Betty. Speech and language outcomes of very preterm infants. Seminars in Fetal and Neonatal Medicine, v. 19, n. 2, p. 78-83, 2014.

WIETHAN, Fernanda Marafiga; MOTA, Helena Bolli; MORAES, Anaelena Bragança de. Correlações entre aquisição do vocabulário e da fonologia: número de palavras produzidas versus consoantes adquiridas. São Paulo: CoDAS, v. 28, n. 4, p. 379-387, 2016a

WIETHAN, Fernanda Marafiga; MOTA, Helena Bolli; MORAES, Anaelena Bragança de. Consonant correlation model: implications to clinical practice. Revista CEFAC. v.18, n. 5, p. 1151-1160, 2016b.

ZERBETO, Amanda B.; CORTELO, Fernando M.; C. FILHO, Élio B. Association between gestational age and birth weight on the language development of brazilian children: a systematic review. Jornal de Pediatria, v. 91, n. 4 , p. 326-332, 2015. 